\title{
Detection of Multidrug Resistance Salmonella spp. from Chicken Meat by Multiplex PCR and VITEK 2 system
}

\author{
KHANZAD KHUDHUR JARJEES ${ }^{*}$, KHANDA OMAR KHUDHUR ${ }^{2}$, SUZAN SABAH YAHIA AL-SAFAR ${ }^{3}$ \\ Department of Food Technology, College of Agriculture, University of Salahaddin, Erbil, Iraq. \\ ${ }^{\star}$ Corresponding Email: khanzad.jarjees@su.edu.krd
}

\begin{abstract}
Salmonellae are highly pathogenic foodborne bacteria able to cause infection even at low doses. Infection by Salmonella from contaminated foods leads to gastrointestinal disease known as salmonellosis. Raw chicken can be a source of human infection if the meat products are not properly handled, stored or cooked. The aim of the present study was to investigate the prevalence of Salmonella Enteritidis and Salmonella Typhymurium serovars in retail raw chicken meat from retail market in Erbil, as well as, to assess their antimicrobial resistance.

A total of 100 raw retail chicken meat samples were collected and plating on Xylose Lysine Deoxycholate and Salmonella-Shigella agar media. In addition, the typical black colonies were identified and stored for further analysis. In addition, Salmonella spp. isolates recovered from the samples were identified and tested for antibiotics susceptibility by using VITEK 2 automated system. The multiplex polymerase chain reaction was employed to detect Salmonella Enteritidis and Salmonella Typhymurium in the meat samples.

Out of 100 raw chicken meat analysed samples, 5 (5\%) were positive for Salmonella Typhimurium, while none of the samples were contaminated with Salmonella Enteritidis.

The resistance levels of the isolates against 12 different antimicrobial agent were tested: all the strains were suscebtible to Imipenem, Meropenem, and Ciprofloxacin. However, the resistance rates in the bacterial isolates were $20 \%$ each for Amikacin, Gentamicin, and Tobramycin, also $40 \%$ and $30 \%$ resistance for Minocycline, and Trimethoprim/Sulfamethoxazole. All isolates of the Salmonella Typhymurium were multiresistant to three or more antimicrobial agents. Preventive measure such as proper temperature control as well as proper handling of raw chicken meat in the market place are crucial to the minimization of any potential health hazard by this foodborne pathogen.
\end{abstract}

\section{INTRODUCTION}

Salmonellae are rod-like Gram-negative bacteria that cause salmonellosis, one of the most important foodborn illnesses worldwide. Salmonella is describe as highly pathogenic bacteria as their infective does is as low 108 to $10^{4}$ cells (perreten, 2005). The intestinal epithelium infection known as salmonellosis is caused by genus Salmonella (Kamarenko et al, 2014; Yang et al, 2016; Eddra et al, 2017).

Salmonella typhi and Salmonella paratyphi are pathogenic exclusive for humans, causing systemic infections and typhoid fever, where as Salmonella enterica serovar Typhimurium cause gastroenteritidis (zhang et al, 2008).

Transmission of infection is generally considered to occur orally. Massive bacterial multiplication occurs within the gut and tissue invasion occurs rapidly (Barrow et al, 1987). Death has been reported to result from a combination of systemic salmonellosis and diarrhea (Hole, 1932). To date, more than 2500 Salmonella serotypes have been identified which half of them belongs to Salmonella enterica serovar Typhimurium. The main sources of transmission of Salmonella spp. are poultry, read-to-eat products, dairy products, fruits, and vegetables (Caponigro et al, 2010; Hur et al, 2012; Keithlin et al, 2015).

Traditionally, $S$. enterica serovar Typhimurium has been thought to be the prototypical broad-host-range serotype, since it is frequently associated with disease in numerous species, including humans, livestock, domestic fowl, rodent and birds (Rabsch et al, 2002). It was estimate that approximately $75 \%$ of human Salmonella infection cases were due to contaminated food products derived from beef, pork, poultry and eggs (Hald et al., 2004). Poultry often become infected through the consumption of contaminated feed, cross-contaminated in brooding houses, or during slaughter and processing (Doyle et al., 2006; Fratamico, 2003).

Salmonella contamination in chicken carcasses can occurred due to contamination is supply chain starting from the process of production, distribution, seller, and handling by consumers. If this chain is not well controlled, it will result the increasing number of whole pathogenic bacteria, include Salmonella (Malorny et al, 2013).

Meat contributes on important proportion in the human diet. It is classified into red and white meat depending on the concentration of myoglobin, a substance in the muscle fiber of animals that is responsible for the meat color (Mancini and Hunt, 2005).

Poultry meat is one of the most popular food products worldwide. Several nutrition factors such as high level of protein and low fat content and favorable content of unsaturated fatty acids contribute to the popularity meat, of which sensory, dietary and economic factors are important (Mulder, 1999).

Salmonella generally grows on media that has water activity above 0.94 and $\mathrm{pH}$ 4.1-9.0 with the optimum $\mathrm{pH}$ 7.0-7.5. Salmonella can grow in a temperature of $5.2-43$ with an optimum temperature of $35-3{ }^{\circ} \mathrm{C}$ and will die on media with salt content above $9 \%$ (FSA, 2007). Salmonella tend to tolerate low temperature for long periods of time (Almashhadany, 2008; Shafini et al, 2017).

Several food animals such as poultry and cattle have been reported to serve as reservoirs for multidrug-resistant Salmonella (Yoke. Kqueen et al, 2008; Arsland and Eyi, 2010; Thung et al, 2016). 
Increased public awareness related to health and the economic impact of foodborn illness demands specific techniques for detection of these food borne pathogens. For Salmonella Typhimurium and Salmonella Enteritidis primers targeting the STM4495 and SEN1392 genes, coding for a putative cytoplasmic protein, which are sensitive and specific for the detection of these serotypes (Lui et al, 2012).

The target of the STM gene is the gene responsible for fimbrial biosynthesis (Clavijo et al, 2006). Long polar fimbrial is absent in all Salmonella strains, specific to Salmonella Typhimutium, long polar fimbrial from Salmonella Typhimutium mediated adhesion and is required for full virulence. Fimbrial is generally responsible for the initial adhesion of Salmonella bacteria to eukariotic cells (Malorny et al, 2003).

The bacteriological method recommended for the diagnosis of Salmonella spp. is labor intensive and requires 4 to 5 days to obtain presumptive positive or negative results, therefore the development of rapid tests is essential for diagnosis and the control of Salmonella spp. (Alcocer \& Oliveira, 2003).

Several techniques for the detection of Salmonella have been developed such as serology test, selective culture medium, and enzyme linked immunosorbent assay (Eriksson and Aspan, 2007). However, these method have several limitations because of low sensitivity and specificity (Kim, 2006).

The polymerase chain reaction (PCR) is a rapid method for detection and identification of pathogens such as Salmonella. These molecular methods, such as multiplex PCR are highly sensitive, very specific, fast and reproducible (Kim et al, 2006).

The emergence of antimicrobial-resistant bacterial pathogens has become a major public health concern. The use of antimicrobials in any venue, including disease treatment and growth promotion in domestic livestock, can potentially lead to widespread dissemination of antimicrobial-resistant bacteria (Gomez-Lus, 1998; Tollefson, et al, 1997; Witte, 1998). There is also the hazard of therapeutic failure due to the increasing incidence of antimicrobial resistance among Salmonella species (Straley et al, 2006; White et al, 2001). Therefore the objective of this study to conduct a survey of chicken meat using multiplex PCR assays for screening to determine the presence of $S$. enterica. The $S$. enterica isolates were characterized to determine their serovars and antibiotic resistance profiles. In this study, we monitored the presence of $S$. enterica serovars including $S$. Typhimurium and $S$. Enteritidis with particular reference to pathogenic potential and profiles for epidemiological analysis and risk assessment.

\section{MATERIAL AND METHOD}

Collection of Samples: A total of 100 sample of raw broiler chicken were collected from various retail markets in Erbil, Iraq from October 2017 to January 2018. samples were collected in a sterile plastic bag, placed into a cold storage box with ice packs and transported to the laboratory. Samples were analysed immediately upon arrival to the laboratory.

Isolation and Identification of Salmonella spp: A 25 gram portion of each sample was aseptically transferred to $225 \mathrm{ml}$ of buffered pepton water (Oxoid, England) and homogenized for $2 \mathrm{~min}$ by stomacher lab-Blender (Bagmixer 400, Interscience, Paris, France). The homogenized sample was incubated at $37^{\circ} \mathrm{C}$ for $24 \mathrm{~h}$ and constituted the preenrichment stage of the isolation. Subsequently, $0.1 \mathrm{ml}$ of this preenrichment culture was added to $100 \mathrm{ml}$ of selenite cystine broth (Oxoid, England) as selective enrichment media and incubated for $24 \mathrm{~h}$ at 37 C , After incubation, a loopful of the enriched cultures was streaked onto Xylose Lysine Deoxycholate (XLD; Oxoid, England and Salmonella-Shigella agar (SSA; Oxoid, England) plates using simultaneously two different selective agar plates. Following incubation, the red with black center on XLD and the colorless colonies with a black center on Salmonella-Shigella agar were counted as suspected Salmonella spp. The presumptive Salmonella colonies were confirmed and identified by using VITEK 2 automated system (bio Merieux).

Antimicrobial susceptibility test: Susceptibility to antimicrobial agents was tested using the VITEK 2 system for the following 12 antimicrobial agents:

Ticacillin, Piperacillin, Piperacillin / Tazobactam, Ceftazidime, Cefepime, Aztreonam, Imipenem, Meropenem, Amikacin, Gentamicin, Tobramycin, Ciprofloxacin, Minocycline, Trimethoprim / Sulfamethoxazole.

DNA extraction: Bacterial DNA was extracted from Salmonella Typhimurium isolates subcultured on nutrient agar plates using DNA extraction kit (geneaid/Korea) according to manufacture's instructions. The DNA extracted samples were stored at $-20{ }^{\circ} \mathrm{C}$ for further use as template for PCR. From this $4 \mu \mathrm{l}$ of template DNA were used directly for the PCR.

Multiplex PCR: The multiplex PCR was standardized for detecting the pathogens under study simultaneously in a single reaction tube containing the two primer sets for these organisms i.e., sen and stm primers for Salmonella Typhimurium and Salmonella Enteritidis (Table1). The total of $25 \mu \mathrm{l} \mathrm{PCR}$ master mix reaction volume was performed containing $4 \mu$ l of genomic DNA, $12.5 \mu$ of $2 X$ GoTaqGreen Master Mix (Promega, USA) and $1.5 \mu \mathrm{l}$ was added for each of the forward and reverse primer for both genes.

PCR amplification was performed as follows: Initial denaturation of $7 \mathrm{~min}$ followed by 35 cycles of final denaturation at $95{ }^{\circ} \mathrm{C}$ for $2 \mathrm{~min}$ at $72{ }^{\circ} \mathrm{C}$ and one cycle of final denaturation at $72{ }^{\circ} \mathrm{C}$ for $10 \mathrm{~min}$ (Table 2).

The PCR products were separated in a 2 percent agarose gel and stained with Safe dye (GenetBio/Korea). The gel was visualised under UV transiluminator (Synegene/UK).

Table 1. The specific sequence oligonucleotide for stm and sen genes

\begin{tabular}{|c|c|c|c|}
\hline Organisms & (Gene name) & DNA sequence of the primer & Suspected size of PCR product (bp) \\
\hline S.Typhimurium & stm & $\begin{array}{l}\text { F 5' GGTGGCAAGGGAATGAA 3' } \\
\text { R 3' CGCAGCGTAAAGCAACT 5' } \\
\text { F 5' GCCACTGTCTGATGCTCTTG 3' }\end{array}$ & $\begin{array}{l}915 \mathrm{bp} \\
656 \mathrm{bp}\end{array}$ \\
\hline S. Enteritidis & & R $3^{\prime}$ GAAAGGCTCCGTGGTTAGT 5' & \\
\hline
\end{tabular}


Table 2. Performance PCR using the thermal cycling conditions for stm and sen genes.

\begin{tabular}{|l|l|l|l|}
\hline Step & Temperature ${ }^{\circ} \mathrm{C}$ & Time & Number of cycles \\
\hline Initial denaturation & $94^{\circ} \mathrm{C}$ & $7 \mathrm{~min}$ & 1 \\
\hline Denaturation & $95^{\circ} \mathrm{C}$ & $1 \mathrm{~min}$ & \multirow{2}{*}{35} \\
\cline { 1 - 2 } Annealing & $60^{\circ} \mathrm{C}$ & $40 \mathrm{sec}$ & \\
\hline Primer Extension & $72^{\circ} \mathrm{C}$ & $2 \mathrm{~min}$ & \\
\hline Final extension & $72^{\circ} \mathrm{C}$ & $10 \mathrm{~min}$ & 1 \\
\hline
\end{tabular}

\section{RESULTS}

Out of 100 raw chicken meat samples were analysed and the presumptive Salmonella colonies were confirmed and identified by the VITEK 2 automated system (Fig. 1 and 2). The multiplex PCR results revealed that 5/100 (5\%) of the samples were found to harbor Salmonella Typhymurium, meanwhile none of the samples was contaminated with Salmonella Enteritidis (Fig. 3).

The antibiotic susceptibility test of Typhimurium revealed Salmonella that all isolates were resistant to Ticacillin, Piperacillin, Piperacillin/Tazobactam, Ceftazidime, Cefepime, Aztreonam. In addition, resistance to Minocycline, Trimethoprim/Sulfamethoxazole, Amikacin, Gentamicin, Tobramycin were 40\%, 40\%, 20\%, 20\%, 20\% respectively, while intermediate resistant to Gentamicin and Tobramycin were $20 \%$. All the isolates were susceptible to Imipenem, Meropenem, Ciprofloxacin (Table 3).

Observation from the presence study indicated that all Salmonella Typhymurium isolates were multi-drug resistant (MRD) isolates, which showed resistance to three antibiotics or more.

Table 3. Antimicrobial susceptibility test for Salmonella Typhimurium isolates

\begin{tabular}{|l|l|l|l|l|l|l|}
\hline No. & Antimicrobial Agents & \multicolumn{5}{|l|}{ No. Isolates } \\
\cline { 3 - 7 } & & 1 & 2 & 3 & 4 & 5 \\
\hline 1 & Ticacillin & R & R & R & R & R \\
\hline 2 & Piperacillin & R & R & R & R & R \\
\hline 3 & Piperacillin/Tazobactam & R & R & R & R & R \\
\hline 4 & Ceftazidime & R & R & R & R & S \\
\hline 5 & Cefepime & R & R & R & R & S \\
\hline 6 & Aztreonam & R & R & R & R & S \\
\hline 7 & Imipenem & S & S & S & S & S \\
\hline 8 & Meropenem & S & S & S & S & S \\
\hline 9 & Amikacin & R & S & S & S & S \\
\hline 10 & Gentamicin & R & I & S & S & S \\
\hline 11 & Tobramycin & R & I & S & S & S \\
\hline 12 & Ciprofloxacin & S & S & S & S & S \\
\hline 13 & Minocycline & R & R & S & S & S \\
\hline 14 & $\begin{array}{l}\text { Trimethoprim/Sulfameth } \\
\text { oxazole }\end{array}$ & R & R & S & S & S \\
\hline
\end{tabular}

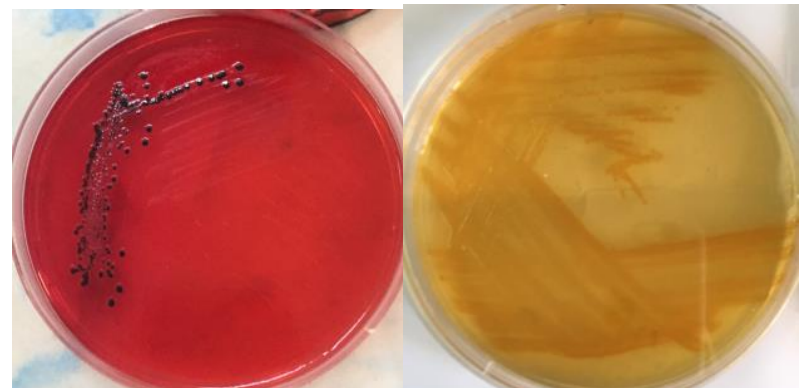

Figure 1. Growth of Salmonella Typhymurium on Xylose Lysine Deoxycholate (XLD) and MacConky agar.

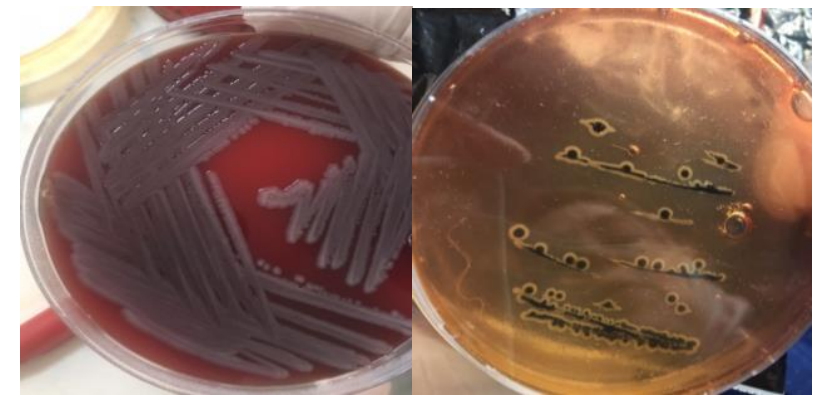

Figure 2. Growth of Salmonella Typhymurium on Blood and Salmonella-Shigella agar (SSA).

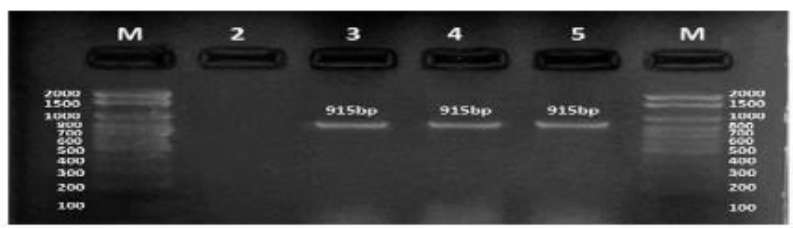

Figure 3. Multiplex PCR specific for Salmonella Typhimurium identification. Lane: 1-6 ladder of 1kb, lane 2: Negative control, Lane 3-5: represent stm (915 bp) gene.

\section{DISCUSION}

In our study, the incidence of Salmonella Typhimurium in raw chicken meat is $5 \%$. Lower results reported by Arsinan and Eyi who isolated $S$. Typhimurium at rate of $26.7 \%$.

This result was in contrast with findings of other previous study, who reported that none of the samples was positive for. $S$ Typhimurium and 4.3 percent of raw chicken meat samples were positive for $S$. Enteritids (Anju et al, 2014).

Variations in sampling methods and culture techniques used to detect the pathogen in individual studies (ray, 2004; Uyttendaele et al,, 1998). Moreover the reasons for difference in the distribution of Salmonella serotypes are complex, as they may be associated with seasonal or demographic factors or the prevalence of a particular species in different product types (Ziprin, 1994). Also, this could be due to the geographical variation such as climate and feed (Pui et al, 2011).

Salmonellae invade and destroy specialized epithelial cells in the host intestine, and migrate to the mesenteric lymph nodes, where they encounter, subsequently survive and replicate within macrophage (Groisman et al, 1999).

Salmonella and other microorganisms have the ability to survive and multiply in internal organs, especially the liver and heart as these areas provide sites where bacterial multiplication can occur without exposure to host defense mechanisms (Gast, 2003). This probably explain the high incidence of Salmonella found in livers and hearts (Abd ElAziz, 2013).

Accordingly, the virulence of bacteria is influenced by both antimicrobial resistance and the presence of virulence 
genes (Huehn et al., 2010; Dong et al., 2014). The emergence of MDR strains of Salmonella are mainly based on the factors of genetic and biochemical mechanisms in order to enhance their survivability by preserving their drug resistance genes (Yang et al., 2010)

Some uses of antimicrobial agents may contribute to the emergence of resistant strains including use in agriculture both as growth-promoting substances in animal feeds and as prophylactics, also the widespread use of antibiotics as a treatment for disease. By overloading various environments with antibiotics, rapid development of drug resistance may result (Arslan and Eye, 2010; Thung et al, 2016).

In this study, MDR Salmonella isolates are prevalent in retail markets. Hence, more attention should be focused on the supervision and control of antimicrobial use, typically in the agriculture and human health care sectors in Erbil (Huehn et al, 2010; Dong et al, 2014). Multiple drug resistance transmitted genetically by plasmids among enteric bacteria is a problem in Salmonella infections. Susceptibility testing in an important adjunct to selecting a proper antibiotics (Jawetz et al, 2007). Liu , (2010) illustrated the specifically gene for identifying et al of $S$. Typhimurium using different genes and found that STM4495 gene was highly target genes between 13 comparison genes.

Molecular technique, such as PCR, are being used routinely in laboratories with bacteriological techniques to provide a more accurate diagnosis in a shorter period of time (Andrade et al, 2010). However, it is essential to invest in research efforts to improve or develop rapid test for the detection of Salmonella spp. in poultry meat to minimize the risks of consumers contracting salmonellosis (Eijkelka et al, 2009).

Poultry products have consistently been identified as important sources of Salmonella infection in humans, because of vertical transfer of infection from breeding hens to progeny is an important aspect of the epidemiology of Salmonella spp. infection within the poultry industry (Bae et al, 2013).

Implementation and maintenance of some control measures like good manufacturing practices (GMP) and hazard analysis and critical control point (HACCP), as well as further strengthening the education of food processors will be necessary, for reducing Salmonella contamination (Sallam et al, 2014).

\section{CONCLUSION}

In this research multiplex PCR has been carried out to identify Salmonella Typhimurium serovar from retail chicken meat. Chicken meat can be become a common vehicle for Salmonella transmission and if inadequate practice of food hygiene and sanitation, Salmonella infection is possible.

Multiple antibiotic resistant Salmonella should be regarded as an issue and the spread should be viewed as a challenge to combat the bacteria and conserving public health.

Moreover, the application of targeting stm and sen genes provides a valuable tool for the rapid identification of Salmonella enterica serovars Typhimurium and Enteritidis from food samples especially milk and dairy products.

\section{REFERENCE}

1. [FSA] Food Safety Authority of Ireland, (2007), Microbiological quality of ice for cooling drinks, 1st National Microbiological Survey. Final Report.

2. Alcocer I. \& Oliveira T. C. R. M. 2003. Rapid detection of Salmonella Enteritidis in food by ELISA assay. Food Science and Technology. 23(3):401-408.

3. Almashhadany DA, 2008. Hygienic Significance of Salmonella among Red Meat in Thamar City. Thamar Uni J 9:73-84.

4. Andrade R. B., Gemelli T., Dall Onder L. P., Cristina k., Brito T., Barboza A. A.L.\&Brito B. G. 2010. Meto dos diagnosticos para as patogenos alimentares; Campylobacter sp., Salmonella sp. e Listeria monocytogenes. Arqs Inst. biologico, sao Paulo, 77:741-750.

5. Anju, P; Latha, C; Sunil, B. and Sethulekshmi, C. (2014). Detection of Salmonella and Yersinia spp.in uncooked retail chicken meat in Kerala by multiplex PCR. Int. J. Curr. Microbiol. App. Sci (2014) 3 (6) 1028-1034.

6. Arslan, S. and Eyi, A. (2010). Occurrence and antimicrobial resistance profiles of Salmonella species in retail meat products. Journal of Food Protection, 73(9), 1613-1617. https: //doi. org/ 10.4315/ 0362-028x-73.9.1613

7. bae, D. H.., Dessie, H.K. Baek, H.J., Kim, S.G., Lee, H.S. and Lee, Y.J.2013. Prevalence and characteristics of Salmonella spp. Isolated from poultry Slaughterhouse in Korea. J. Vet. Med. Sci. 75:1193-1200.

8. Barrow, P.A. : Huggins, M.B.; Lovell, M.A. and Simpson, J.M. (1987). Observations on the pathogenesis of experimental Salmonella Typhimurium infection in chickens. Res. Vet. Sci., 42:194-199.

9. Caponigro V., Ventura M., Chiancone I., Amato L., Parente E., Pioro F. (2010). Variation of microbial load and visual quality of ready-to-eat salads by vegetable type, season, processor and retailer. Food Microbiology. 27:1071-1077.

10. Dang, P., Zhu, Liang, R., Niu, L., Zhang, Y.,, et al. (2014). Prevalence and profile of Salmonella from samples along the production line in Chines beef processing plants. Food Control, 27:87-93.

11. Doyle MP, Erickson MC (2006) Reducing the carriage of foodborne pathogens in livestock and poultry. Poultry Sci 85:960-973.

12. Ed-dra, A., Filali, F. R., Karraouan, B., El Allaoui, A. Aboulkacem, A., and Bouchrif, B. (2017). Prevalence, molecular and antimicrobial resistance of Salmonella isolated from sausages in Meknes, Morocco. Microb. Pathg. 105, 340-345. doi: 10.1016/j. micpath. 2017. 02. 042

13. Eijkelkamp J.M. Aarts H.J.M.\& vanderFels-Klerx H.J. 2009. Suitability of rapid detection methods for Salmonella in poultry slaughterhouses. Food Ana. Methods 2(1):1-13.< http://dx.doi.org/10.1007/s 12161-008-9040-5>

14. Eriksson E. Aspan A. Comparison of culture, ELISA, and PCR techniques for Salmonella detection in faecal samples for cattle, pig, and poultry. BMC Vet Res. 2007; 3:1-19.

15. Fratamico PM (2003) Comparison of culture, polymerase chain reaction (PCR), TaqMan Salmonella, and Transia Card Salmonella assays for detection of Salmonella spp. in naturally-contaminated ground chicken, ground turkey, and ground beef. Mol Cell Probes 17:215-221.

16. Gast R. Diseases in poultry. 11th ed. united States; Wiley; 2003, Salmonella Typhmurium in retail chicken meat and chicken giblets Asian Pac J Trop Biomed; 3(9): 678-681.

17. gomez-Lus, R. 1998. Evolution of bacterial resistance to antibiotics during the last three decades. Int. Microbiol. 1:279-284.

18. Groisman, E.A,; Blanc-Portard, AB. and Uchiya, K. (1999). Pathogenicity islands and the evolution of Salmonella virulence. In pathogenicity Islands and Other Mobile Virulence Elements, 127-150. 
19. Hald T, Vose D, Wegener HC, Koupeev T (2004) A Bayesian approach to quantify the contribution of animalfood sources to human salmonellosis. Risk Anal 24:255-269.

20. hole, N. (1932). Salmonella infections in ducklings. J. Comp. Path. Ther., 44:161-71.

21. Huehn, S., La Ragione, R.M., Anjum, M., Saunders, M. Woodward, M.J., Bunge, C., et al. (2010). Virulotyping and antimicrobial resistance typing of Salmonella enterica serovars relevant to human health in Europe. Foodborn Pathog. Dis. 7, 523-535. doi:10.1089/ fpd. 2009.0447.

22. Hur J., Jawale C., Lee J.H. (2012). Antimicrobial resistance of Salmonella isolated from food animals. a review. Food Research International. 45:819-830.

23. Jawetz, M.; Adelberg S.; Brooks, G.F.; Carroll, K.C.; Butel, J.S. and Morse, S.A. (2007). Medical Microbiology. 24TH edition. McGraw-Hill Company, Inc., New York, SanFrancisco, Lisbon, London.

24. Keithlin J. Sargeant J.M., Thomas M.K., Fazil A. (2015). Systematic review and meta-analysis of the proportion of non-typhoidal Salmonella cases that develop chronic sequelae. Epidemiology and Infection. 143:1333-1351.

25. Kim S, Fry JG, Hu J, Fedorka-Cray PJ, Gautom R, Boyle D.S. Multiplex PCR-based method for identification of common clinical serotypes of Salmonella enterica subsp. Enterica. J Clin Microbiol. 2006; 44:3608-15.

26. Kramarenko, T., Numoja, I., Karssin, A., Meremae, K., Horman, A., and Roasto, M. (2014). The prevalence and serovar diversity of Salmonella in various food products in Estonia. Food Control. 42, 43-47. doi: 10. 1016/j. food cont. 2014. 01. 032.

27. Liu, B., Zhou, X., Zhang. L., Lui, W., Dan, X., Shi, C. and Shi, X. 2012. Development of a novel multiplex PCR assay for the identification of Salmonella enterica Typhymurium and Enteritidis. Food Control. 27:87-93.

28. Liu, B.; Zhang, L.; W.; Dan, X.; Shi, C. and Shi, X. (20112). Development of a novel multiplex PCR assay for the identification of Salmonella enterica Typhimurium and Enteritidis. Food Control, 27; 87-93.

29. Malorng B, Made D, Charlotta L, Real-time PCR Detection of food-born Pathogenic Salmonella spp. In: Rodriguez DL, editor. real-time PCR in food Science. Norfolk (UK): Caister Academic press. pp57-78.

30. Mancini, R. A. and hunt, M. (2005). Current research in meat color. Meat Science, 71(1), 100-121. https:// doi.org/10.1016/j. meat sci. 2005.03.003.

31. Mudler RW AW. Hygiene during transport, slaughter and processing. In: Richardson RI, Mead GC, editors. Poultry meat science: Poultry science symposium series. vol. 25. Massachusetts: CABI Publishing; 1999.pp. 277-283.

32. Perreten. V.(2005). Resistance in the food chain and in bacteria from animals: relevance to human infections. In White, D. G.., Alekshun, M. N. and McDermott, P. F. (Eds). Frontiers in Antimicrobial Resistance: A Tribute to Stuart B. Levy, P. 446-464. Washington, DC: American Society of Microbiology. https:// doi.org /10.1128/978155817572.ch34.

33. Pui, C.F. Wong, W.C., Chai, L.C. Nillian, E., Ghazali, F.M., Cheah, Y.K., Nakaguch, Y., Nishibuchi, M. and Son, R. (2011). Simultaneous detection of Salmonella spp., Salmonella Typhi and Salmonella Typhimurium in sliced fruits using multiplex PCR. Food Control, 22(2), 337-342. https;// doi. org /j. foodcont. 2010.05.021.

34. Rabsch, Wolfgang; Andrews, H.L.; Kingsley, R. A.; Prager, R.; Tschape, H.; Adams, L.G. and baumler, A.J. (2002).
Salmonella enterica Typhimurium and Its Host-Adapted Variants. "MSM" Infection \& Immunity, 70(5): 2249-2255.

35. Ray, B. 2004. Fundamental food microbiology. CRC Press, Boca Raton, FL.

36. Sallam, K. I., Mohammed, M. A., Hassan, M. A., and Tamura, T. (2014). Prevalence, molecular identification and antimicrobial resistance profile of Salmonella serovars isolated from retail beef products in Mansoura, Egypt. Food Control. 38, 209-214. doi:10.1016/j. foodcont.2013.10.027.

37. Shafini AB, Son R, Mahyudin NA, Rukayadi $Y$, Tuan Zainazor TC, 2017. Prevalence of Salmonella spp. in chicken and beef from retail outlets in Malaysia. Int Food Res J 24:437-49.

38. Straley, B. A., S. C. Donaldson, N. V. Hedge, B. M. Jayarao, A. A. Sawant, V. Srinivasan, and S. P. Oliver. 2006. Public health significance of antimicrobial-resistant gram-negative bacteria in raw bulk tank milk. Foodborne pathog. Dis. 3:222233.

39. Thung, T.Y., Mahyudin, N.A., Basri, D.f., Wan Mohamed Radzi, C.W.J., Nakaguchi, Y., nishibuch:, M. and Son, R. (2016). Prevalence and antibiotic resistance of Salmonella Enteritidis and Salmonella Typhimurium in raw chicken meat at retail markets in Malaysia. Poultry Science, 95(8), 18881893. http://doi.org/10.3382/ps/pew 144.

40. Thung, T.Y., Son, R., Mahyudin, N.A., Rukayadi, Y., Zakaria, Z., Mazlan, N., Tan, B.H., Lee, E., Yeoh, S.L., Chin, Y.Z., Tan, C.W., Kuan, C.H., Basri, D.F. and Wan Mohamed Radzi, C.W.J. (2017). Prevalence, virulence genes and antimicrbial beef in Selangor, Malaysia. Frontiers in Microbiology, 8, 2697. https: //doi.org/10.3389/ fmicb. 2017.02697.

41. Tollefson, I., S. F. Altekruse, and M.E. Potter. 1997. Therapeutic antibiotics in animal feeds and antibiotic resistance. Rev. Sci. Tech. 16:709-715.

42. Uyttendaele, M. R., J. M. Debevere, R. M. Lips, and K.D. Neyts. 1998. Prevalence of Salmonella in poultry carcasses and their products in Belgium. Int. J. Food Microbiol. 40:1-8.

43. Witte, W. 1998. medical consequences of antibiotic use in agriculture. Science 279:996-997.

44. Yang, B., Qu, D., Zhang, X,. SHen, J., Cui, S., Shi, Y., et al. (2010). Prevalence and characterization of Salmonella serovars in retail meats of marketplace in Shaanxi, China. Int. J. Food Microbiol. 141, 63-72.

45. Yang, X., Hunag, J., Wu, Q., zhang, J., Liu, S., Guo, W., et al (2016). Prevalence, antimicrobial resistance and genetic diversity of Salmonella isolated from retail ready-to-eat foods in Cina. Food Control. 60, 50-56. doi: 10.1016/j. food cont.2015.07.019

46. Yoke-Kqueen, C., Learn-Han, L., Noorzaleha, A.S., Son, R. Sabrin, S., Jiun-Horng, S. and Chai-Hoon, K. (2008). Characterization of multiple-antimicrobial- resistant Salmonella enterica subsp. enterica isolated from indigenous vegetables and poultry in Malaysia. Letters in Applied Microbiology, 46(3), 318-324. https; // doi.org/10.1111/j.1472-765x. 2007.02311.x

47. Zhang XL, Jeza VT, Pan Q. Salmonella typhi: from a human pathogen to a vaccine vector. Cell Mol Immunol, 2008; 5: 917.

48. Ziprin, R. L. 1994. Salmonella p. 253-318. In Y. I. Hui, J.R. Gorham, K.D. Murrell, D.O. Cliver (ed), Foodborn disease handbook, vol. 1. Marcel Dekker, New York. 